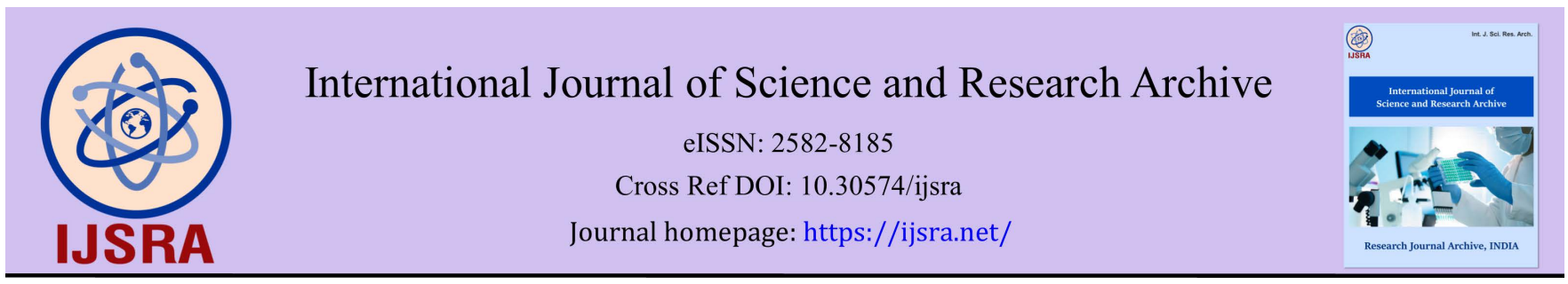

(CASE REPORT)

\title{
Benign mixed tumour of the upper lip - Report of a rare case
}

\author{
Maria C. Michali *, Lentiona V. Basiari, Konstantina Z. Mparka and Ioannis D. Komnos \\ School of Medical Sciences, Faculty of Medicine, Department of Otorhinolaryngology, University Hospital of Ioannina, \\ Epirus, Greece.
}

International Journal of Science and Research Archive, 2021, 02(01), 149-155

Publication history: Received on 07 February 2021; revised on 11 March 2021; accepted on 14 March 2021

Article DOI: https://doi.org/10.30574/ijsra.2021.2.1.0038

\begin{abstract}
Introduction: Pleomorphic adenomas are the most common non-malignant neoplasms of salivary gland tumours that present mixed histopathological patterns. The purpose of our study was to report an unusual case of a pleomorphic adenoma which was located in the upper lip that had been initially considered as cyst.

Case report: The patient was a middle aged man who had a painless, slow-growing swelling in the upper lip. At first, the round-shaped and mobile mass was considered as cystic lesion. However during the operation, it was discovered instead of a cyst, an encapsulated solid tumour that demonstrated both epithelial and mesenchymal cells in histopathology and the diagnosis of pleomorphic adenoma was set. One year postoperatively the patient had no recurrence of tumour.
\end{abstract}

Conclusions: Occurrence of intraoral lip swelling could be attributed, even rarely, to benign mixed tumours. Despite its nonmalignant features, these masses have a relatively low but still existing risk for recurrence or malignant transformation and thus in similar cases a systematic follow-up should be performed even years after surgery.

Keywords: Mixed tumor; Pleomorphic adenomas; Benign tumors of the lip; Tumours of minor salivary glands

\section{Introduction}

Pleomorphic adenomas (PA) are benign neoplasms which account for 50-70\% of all major and minor salivary gland tumours [1-6]. Nearly $80-85 \%$ of all PAs are found in major salivary glands (80\% in parotid glands and less than $5 \%$ in submandibular glands) and the rest $15-20 \%$ in the minor salivary glands of oral or nasal cavity and upper respiratory or gastrointestinal tracks [6-8]. Regarding the minor salivary glands, palate is the most common location of PAs (more than 50\%) whereas lips, buccal mucosa, tongue, gingiva, pharynx, nasal cavity and larynx have been also reported as potential places [4, 7-13]. Typically PAs occur in women (female/male ratio: 2.5/1) between 30 and 60 years old. However they may affect patients of all ages and sex [1, 8, 14-15].

The etiology and pathophysiology of pleomorphic adenomas remain still under investigation. However chronic exposure to radiation, viruses or clonal chromosome abnormalities with aberrations especially regarding $8 q 12$ and 12q15, have been associated with the development of PAs [1, 4, 16-17]. Histologically, the microscopic architectural pattern of these masses is consisted of epithelial, myoepithelial and mesenchymal or stromal components which explains the term pleomorphic or benign mixed tumours that have been given to these neoplasms [1, 18-19].

Clinically, the symptoms of PAs depend on the involved anatomical area. In the majority of cases, they are asymptomatic or painless masses that develop with slow growth rate [1, 18, 20-22]. Recurrence after excision varies from 0 -10\%,

\footnotetext{
* Corresponding author: Maria MIchali

School of Medical Sciences, Fuculty of Medicine, Department of Otorhinolaryngology, University Hospital of Ioannina, Epirus, Greece. 
whilst the risk of malignant transformation is reported in less than 6\% [22-24]. The aim of the current study was to present a very rare case of a pleomorphic adenoma removed under local anesthesia from the upper limb of a male patient in his fifth decade of life, which was initially suspected to be as a simple cyst.

\section{Case report}

A 49-year-old male was referred to our department with a painless swelling nearly in the midline of the upper lip, which was causing little discomfort during mastication, and had been enlarged very slowly but gradually over the last months. He had claimed that the presence of this lesion had been noted six months ago. Regarding his medical history, apart from smoking, there was no reference of any other addiction, systematic or regional diseases, fever, trauma, known allergies, or other associated symptoms. No haemorrhage from the nodule, or sleep disturbances had been referred and the family history was negative for intraoral tumours.

On clinical examination, a well circumscribed, hard but rather mobile, round mass, $2 \mathrm{~cm}$ in diameter, was observed in the midline of the upper lip which corresponded to the reported by the patient, visible swelling [Figure 1]. The overlying labial mucosa was slightly purple and the skin over the lesion was normal in appearance. The fold was painless and nonfluctuant on palpation. In addition, there were no palpable lymph nodes in neck and head and the rest of otorhinolaryngological and systemic examination did not indicate any other abnormality. Moreover, laboratory examinations were within normal values.

\subsection{Please place figure 1 here}

The patient was recommended surgical excision of the lesion which was perfunctorily thought to be a cyst. Two weeks after the first visit, the patient entered the hospital to proceed with the excision under local anesthesia and aseptic condition. However, after the initial, horizontal splitting incision of the mucosa just over the lesion and dissection of soft tissues as shown in Figure 2, the surgeon identified the presence of a well-defined and fully encapsulated concrete mass which was $1.5 \times 1.5 \mathrm{~cm}$ in size, yellow-white in color and its margins were reaching the epidermis [Figure 3]. The mass was en-bloc resected in clinically safe borders, without any difficulty and the wound was closed with absorbable sutures [Figure 4]. Postoperatively, the patient was prescribed antibiotics (500 mg cefuroxime) twice per day for seven days but no analgesics were taken. Additionally, no postoperative complications were observed and the healing was satisfactory.

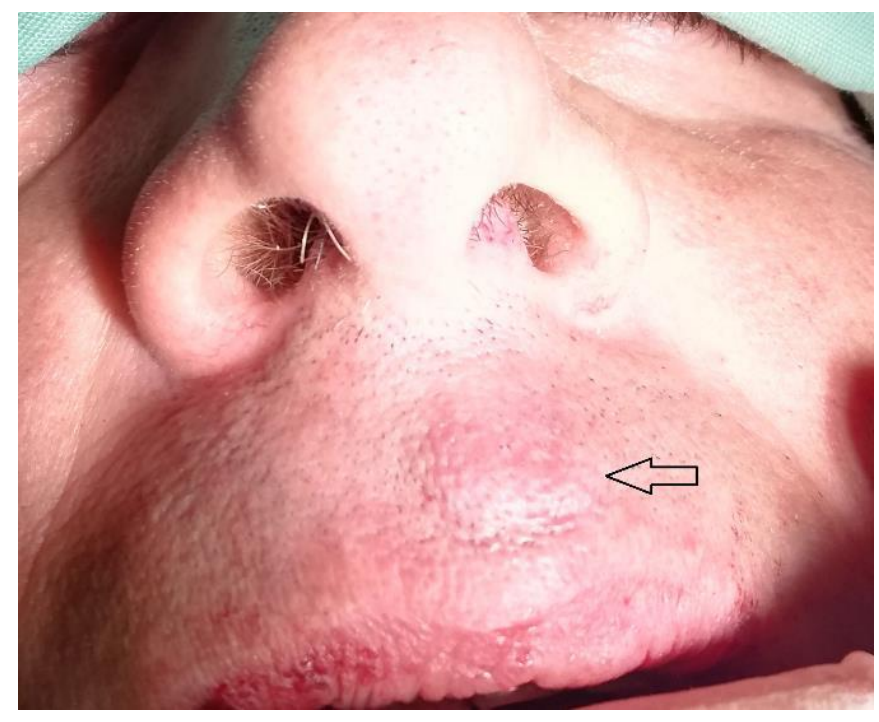

Figure 1 Upper lip swelling, marked with a black arrow.

\subsection{Please place figures 2 and 3 here}

The histopathological examination of the resected specimen revealed an encapsulated lesion with a mixture of epithelial and mesenchymal cells [Figure 5]. No cell atypia, mitoses or any other sign of malignancy was found. The histological findings were typical for the diagnosis of pleomorphic adenoma that had been totally removed. 


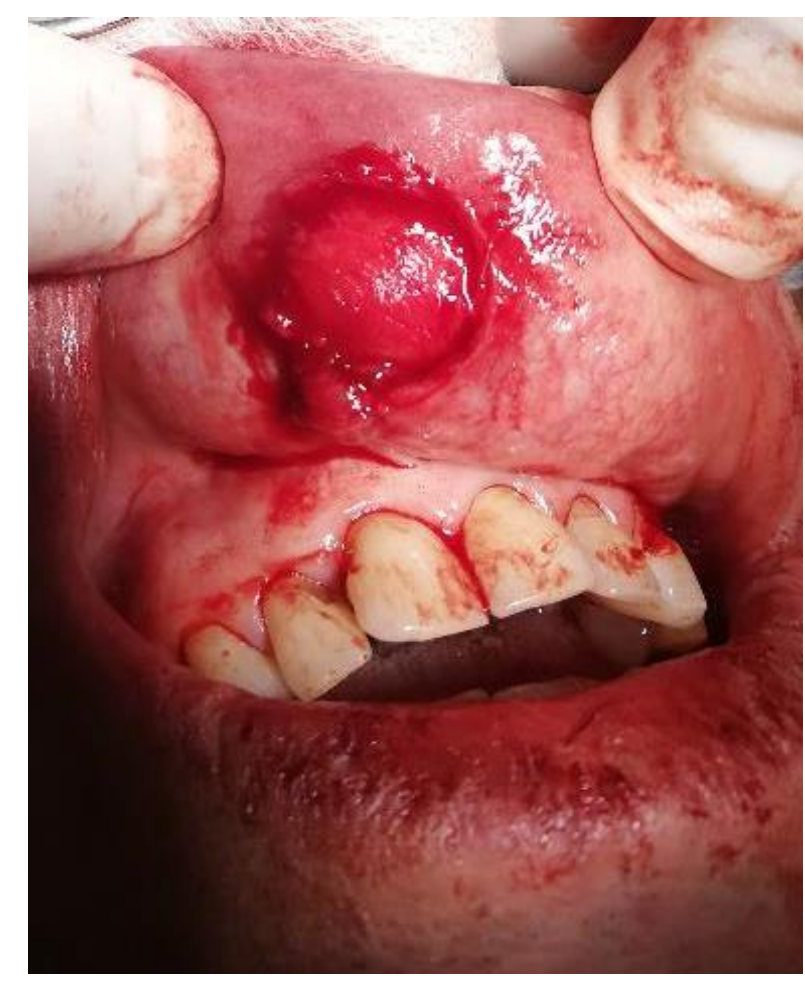

Figure 2 Intraoperative image of the round encapsulated tumour.

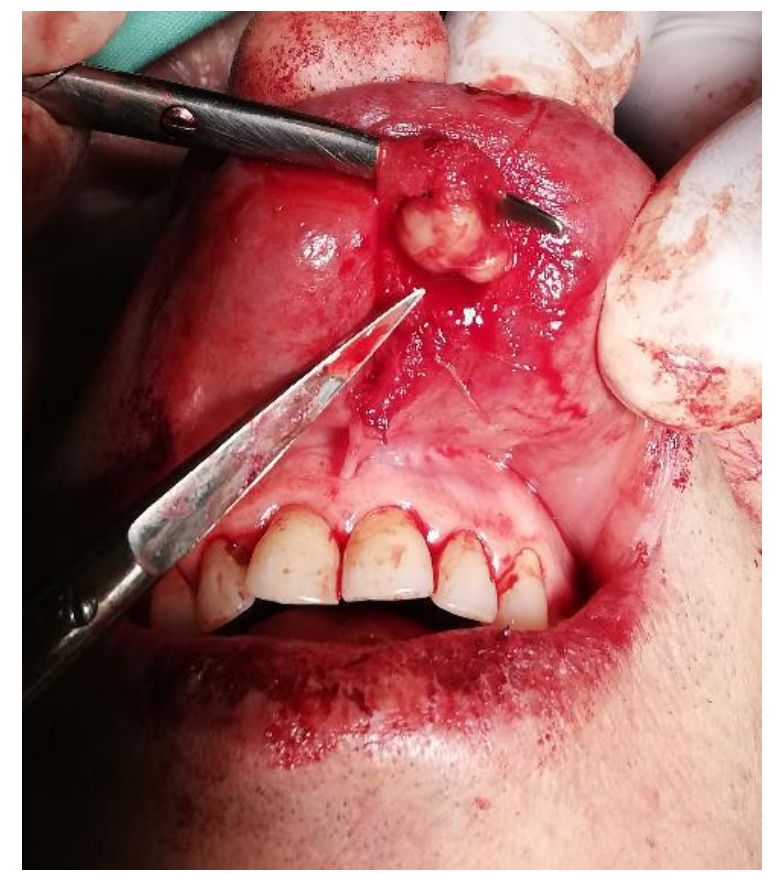

Figure 3 Intraoperative image demonstrating the excision and morphologic characteristics of tumour.

\subsection{Please place figure 4 and 5 here}

A periodical routine control, every month for the first six months and then every three months for checking any potential recurrence of the tumour was performed. After a follow-up of 1 year the patient was free of symptoms without any sign of lesion recurrence. 
Regarding ethics approval, the present case report study had been approved by the ethical board of our University Hospital. The patient was in agreement with the surgical procedure and gave his written informed consent for participation in accordance with our University's Medical School Institutional Review Board procedures.

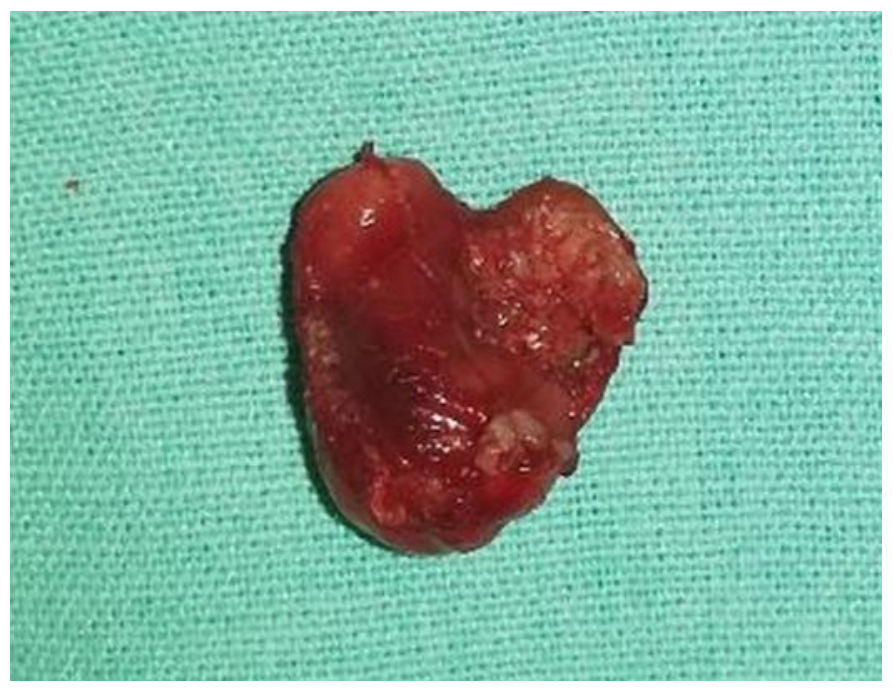

Figure 4 Macroscopic picture of the tumour.
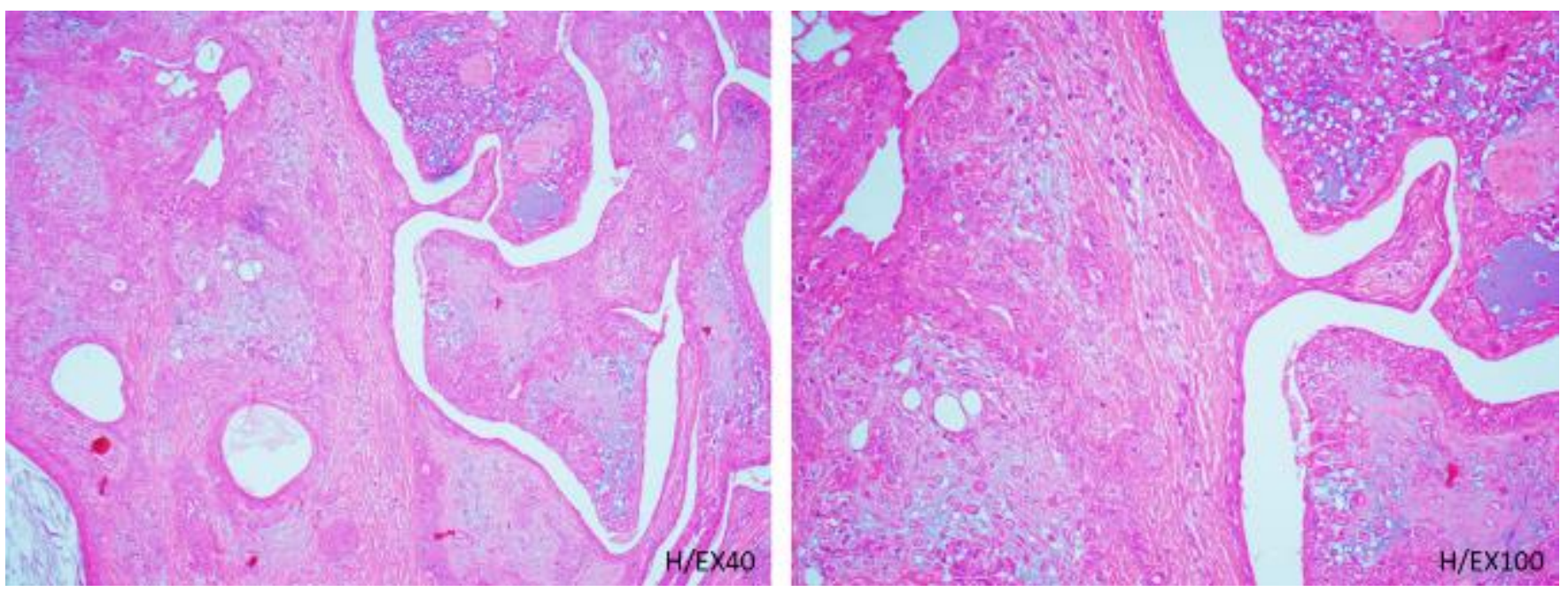

Figure 5 Histopathological characteristics of pleomorphic adenoma, hematoxylin and eosin stain magnification X40 and X100

\section{Discussion}

Lip swelling is a clinical entity that could be attributed to different causes, mostly benign or even malignant. Differential diagnosis of nonmalignant aetiologies include lipomas, fibromas, neurofibromas, or other benignant mesenchymal tumors, oral cysts (mucoceles, salivary duct cysts, dermoid cysts), benign minor salivary gland tumors (such as pleomorphic adenomas), chronic inflammation after intraoral trauma or reaction to foreign bodies and tuberculosis, amongst others [4, 25-26]. On the other hand, adenoid cystic carcinomas, mucoepidermoid carcinomas or other malignant mesenchymal tumours such as rhabdomyosarcomas are the most common cancerous causations of lip swelling $[4,25]$.

In our case, based on clinical evaluation, the swelling in the upper lip was initially mistaken as cystic lesion. However, the intraoperative benign features of the neoplasm along with the postoperative histopathological findings confirmed the presence of the pleomorphic adenoma in this anatomic region. Generally, for the diagnosis of PAs, a combination of 
complete medical history, thorough clinical evaluation, histopathological examination and cytology, is required [27]. Therefore despite the clinical elements, in order to differentiate benign from malignant masses, a biopsy should always be executed [27].

Noncancerous masses present frequently as asymptomatic, well-encapsulated, mobile nodules that grow very slowly without adherence to deep or superficial tissues [4]. Invasive malignant neoplasms are usually symptomatic and painful, with fast and irregular development, abnormal margins, and adherence to surrounding layers or potential lymph node involvement. Ulceration or even bleeding from the overlaying mucosa may also be reported [25].

More than $80 \%$ of the upper lip tumours such as pleomorphic adenoma have been found to be benign and less than $20 \%$ malignant $[8,10]$. On the contrary, in the lower lip a tendency for occurrence of cancerous neoplasms has been detected [10]. The differences of embryonic development between upper and lower lip has been proposed for this distinctive pathogenesis [8, 28-29].

In cases of initially benign PAs that display alterations in their morphological characteristics, like accelerated size expansion or painful ulceration; malignant transformation should be suspected and histopathological examination should be performed for checking potential cellular atypia that indicates malignancy of PAs [4]. Carcinoma ex pleomorphic adenoma, true malignant mixed tumour or carcinosarcoma and metastasizing mixed tumour are the most common types of cancerous pleomorphic adenomas [30] and their existence has been attributed to neglected, untreated nonmalignant PAs or after incomplete surgical removal [25, 31].

Therefore, the treatment option for benign PAs is not simple tumour enucleation, but complete surgical incision of the neoplasm and its capsule with sufficient normal surrounding tissue margins, followed by biopsy and histopathological examination [31]. Otherwise, especially when leaving residual tumor, there is a higher risk of recurrence [23, 30-31]. Apart from incomplete neoplasm incision, or insufficient surgical procedure such as enucleation alone, recurrence of PAs may also be the result of pseudopods in the capsule or intraoperative tumor implantation [30-31].

In our patient, despite the initial misdiagnosis and lack of any imaging assessment, the encapsulated mass was completely removed and no local recurrence was observed one year after the operation. However, taking into account the potentiality of salivary gland tumors to reoccur years after their removal, the patient will be followed-up for a long period of time [4].

\section{Conclusion}

Conclusively, intraoral upper lip swelling could be caused by the unusual case of pleomorphic adenoma. Because of its mixed topographical and histological features, the diagnosis is an intriguing issue not only for the surgeon but also for the histopathologist. Despite the benign aspect of the tumour, treating surgeons should always concern about its high potential of recurrence or malignant transformation specifically after late diagnosis or incomplete treatment.

\section{Compliance with ethical standards}

\section{Acknowledgments}

No acknowledgments.

\section{Disclosure of conflict of interest}

All authors declare that they have no competing interests.

\section{Statement of informed consent}

The patient gave his informed consent for participation in accordance with our Institutional Review Board procedures.

\section{References}

[1] Forty MJ, Wake MJ. Pleomorphic salivary adenomain an adolescent. Br Dent J. 2000; 188: 545-546.

[2] Sreenivas DS. Pleomorphic adenoma of the palate: A case report. J Indian Dent Assoc. 2011; 5(4): 557-558. 
[3] To EW, Tsang WM, Tse GM. Pleomorphic adenoma of the lower lip: report of a case. J Oral Maxillofac Surg. 2002; 60: 684-686.

[4] Spiro RH. Salivary neoplasms: overview of a 35-year experience with 2,807 patients. Head Neck Surg. 1986; 8(3): 177-184.

[5] Friedrich RE, Li L, Knop J, Giese M, Schmelzle R. Pleomorphic adenoma of the salivary glands: Analysis of 94 patients. Anticancer Res. 2005; 25: 1703-1705.

[6] Gana P, Masterson L. Pleomorphic adenoma of the nasal septum: A case report. J Med Case Rep. $2008 ; 2: 349$.

[7] Bailey BJ. Head and neck surgery. In: Otolaryngology, chap 107, 3rd ed. Lippincott Williams and Wilkins, Philadelphia. 2001.

[8] Eveson JW, Cawson RA. Salivary gland tumours. A review of 2410 cases with particular reference to histological types, site, age and sex distribution. J Pathol. 1985; 146: 51-58.

[9] Pires FR, Pringle GA, de Almeida OP, Chen SY. Intra-oral minor salivary gland tumors: a clinicopathological study of 546 cases. Oral Oncology. 2007; 43(5): 463-470.

[10] Waldron CA, el-Mofty SK, Gnepp DR. Tumours of the intraoral minor salivary glands: a demographic and histologic study of 426 cases. Oral Surg Oral Med Oral Pathol. 1988; 66(3): 323-333.

[11] Alves FA, Perez DE, Almeida OP, Lopes MA, Kowalski LP. Pleomorphic adenoma of the submandibular gland: clinicopathological and immunohistochemical features of 60 cases in Brazil. Arch Otolaryngol Head Neck Surg. 2002; 128(12): 1400-1403.

[12] Byakodi S, Charanthimath S, Hiremath S, Kashalikar JJ. Pleomorphic adenoma of palate: a case report. Int J Dent Case Rep. 2011; 1: 36-40.

[13] Sreenivas DS. Pleomorphic adenoma of the palate: A case report. J Indian Dent Assoc. 2011; 5(4): 557-558.

[14] Toida M, Shimokawa K, Makita H, Kato K, Kobayashi A, Kusunoki Y, Hatakeyama D, Fujitsuka H, Yamashita T, Shibata T. Intraoral minor salivary gland tumors: a clinicopathological study of 82 cases. Int J Oral Maxillofac Surg. 2005; 34: 528-532.

[15] Przewoźny T, Stankiewicz C. Neoplasms of the parotid gland in northern Poland, 1991-2000: an epidemiologic study. Eur Arch Otorhinolaryngol. 2004; 261: 369-375.

[16] Manor E, Joshua BZ, Brennan PA, Bodner L. Chromosomal aberrations in minor salivary gland pleomorphic adenoma. J Oral Maxillofac Surg. 2012; 70: 2798-2801.

[17] Martinelli M, Martini F, Rinaldi E, Caramanico L, Magri E, Grandi E, Carinci F, Pastore A, Tognon M. Simian virus 40 sequences and expression of the viral large T antigen oncoprotein in human PAs of parotid glands. Am J Pathol. 2002; 161(4): 1127-1133.

[18] Farina A, Pelucchi S, Grandi E, Carinci F. Histological subtypes of pleomorphic adenoma and age frequency distribution. Br J Oral Maxillofac Surg. 1999; 37: 154-155.

[19] Margaritescu C, Raica M, Florescu M, Simionescu C, Surpateanu M, Jaubert F, Bogdan F. The ultrastructural aspects of neoplastic myoepithelial cell in pleomorphic adenomas of salivary glands. J Cell Mol Med. 2004; 8: 369381.

[20] Bentz BZ, Hughes CA, Ludemann JP, Maddalozzo J. Masses of the salivary gland region in children. Arch Otolaryngol Head Neck Surg. 2000; 126: 1435-1439.

[21] Ansari MH: Salivary gland tumors in an Iranian population: A retrospective study of 130 cases. J Oral Maxillofac Surg. 2007; 65: 2187-2194.

[22] Qureshi MY, Khan TA, Dhurjati VN, Gaddikeri K, Khany MZ. Pleomorphic adenoma in retromolar area: A very rare case report and review of literature. J Clin Diagn Res. 2016; 10: ZD03-05.

[23] Daniels JS, Ali I, Bakri IM Al, Sumangala B. Pleomorphic adenoma of the palate in children and adolescents: A report of 2 cases and review of the literature. J Oral Maxillofac Surg. 2007; 65: 541-549.

[24] Andreasen S, Therkildsen MH, Bjørndal K, Homøe P. Pleomorphic adenoma of the parotid gland 1985-2010: a Danish nationwide study of incidence, recurrence rate, and malignant transformation. Head Neck. 2016; 38: E1364-1369. 
[25] Vicente OP, Marques NA, Aytes LB, Escoda CG. Minor salivary gland tumors: A clinicopathological study of 18 cases. Med Oral Patol Oral Cir Bucal. 2008; 13: 582-588.

[26] Patel H, Bhatia L, McQueen G, Moorman J. Persistent upper lip swelling caused by foreign body infection: a case report. South Med J. 2008; 101(6): 651-653.

[27] Cerulli G, Renzi G, Perugini M, Becelli R. Differential diagnosis between adenoid cystic carcinoma and pleomorphic adenoma of the minor salivary glands of palate. J Craniofac Surg. 2004; 15(6): 1056-1060.

[28] Aver LM, Chaves SB, Neutzling AP, Etges A. Intraosseous pleomorphic adenoma: case report and review of the literature central pleomorphic adenoma of the maxilla. Medicina Oral. 2002; 7: 164-170.

[29] Shrestha A, Reddy NS, Ganguly SN. Pleomorphic adenoma of the upper lip: A case report. Nepal Med Coll J l. 2010; 6: 51-53.

[30] Tzermpos F, Chatzichalepli C, Cocos A, Kleftogiannis M, Zarakas M, Chrysomali E. Atypical Presentation of an Upper Lip Pleomorphic Adenoma: Case Report. Acta Stomatol Croat. 2014; 48(1): 48-53.

[31] Vlaykov A, Vicheva D. Nasal pleomorphic adenoma - a case report. Int J Sci Res. 2015; 4: 77-79. 